\title{
Assessment of Women's Knowledge and Practices toward Family Planning at Maternity Hospitals in Baghdad City
}

\author{
Fatima Fadel Benyian
}

Assistant Instructor, Maternal and Neonatal Nursing Department, College of Nursing, University of Baghdad

\begin{abstract}
Family planning is the decision that couples make about if they want to have children, when, how many children, and how they are spaced. Knowledge is necessary to make decisions and know how to avoid conception. Some couple needs counseling because contraception has failed.

Objectives: To assess women's knowledge and practices about family planning and find out the association between women's knowledge and practices with some study variables.

Method: Descriptive study was conducted from October 2019 to March 2020 at maternity hospitals in Baghdad city. Non probability (purposive sample) was used to collect the data from (79) women who attending outpatient clinics at maternity hospitals in Baghdad city. A questionnaire was designed by the researcher. A pilot-test is conducted in order to determine the reliability of the questionnaire in a sample of (20) women who were excluded from the study sample. Data was analyzed through the use of SPSS version 20 .
\end{abstract}

Results: The results revealed that the highest percentage (49.4\%) of women's age was (30-39) years. More than two third of them (69.6\%) are graduated from college. The higher percentages (63.3) have knowledge and $(58.2 \%)$ used a family planning method. There are no statistical significant differences between women's knowledge and practice.

Conclusion: This study finds that the women have knowledge and used a family planning method, but there are no significant differences between women's knowledge and practices.

Recommendations: Based on study findings the source of knowledge from the internet and they choose a type of family planning based on family and friends advice so the researcher recommend to activate the role of health care professional especially doctors and nurses to provide scientific knowledge and counseling to couples to choose the most appropriate method.

Keywords: Knowledge, Practices, Family Planning Method, Women.

\section{Introduction}

Family planning is so important that many national health goals speak directly to this area of care. Intentional pregnancy is important for a child's health, because unintended or misused pregnancy leads to short-term and long-term consequences such as a low rate of antenatal care visit, breastfeeding, and may be less eager to protect her fetus from harmful substances. A child of unintended pregnancy is at greater risk of low birth weight, dies in the first year, being abused, and does not receive sufficient resources for healthy growth and development ${ }^{[1]}$.

Having children is one of the most important roles and performance of a woman, however, for a physiological process; pregnancy is an unexpected, unpleasant, unplanned and high risk and can cause disability and death ${ }^{[2]}$.

Family planning deals with the woman's reproductive health, adequate birth spacing, avoiding 
unwanted pregnancies and abortions, preventing sexually transmitted diseases, and improving the quality of life of the mother, fetus and family as a whole ${ }^{[3]}$.

A woman's decision to use family planning method and choosing the method are affected by several complex psychosocial and structural factors, including contraceptive beliefs, negotiation ability with partner about using a contraceptive method, and access to services of reproductive health. Knowledge is an important factor that affects decision making for using a contraceptive method ${ }^{[4]}$.

Globally, perinatal mortality about (40\%) of infant mortality yearly, resulting in about three million stillbirths and four million neonatal deaths. Perinatal mortality rate is high in low-income countries, with an average (50 deaths/1000 live births), compared with (ten deaths/1000 live births) in high-income countries. Family planning has been shown that reduce maternal and infant mortality, however contraceptive use in many resource-limited countries ${ }^{[5]}$.

Family Planning services in Iraq need more efforts to be improved, as the indicators include: Modern Contraceptive Prevalence Rate (28\%), unmet needs (22\%), Adolescents Birth Rate (60\%), and unwanted pregnancies (12\%). Total Fertility Rate is (4.6) live births per woman and population growth Rate three percent. From above, it's clear that indicators negatively affecting the women and family health and also the development plans ${ }^{[6]}$.

\section{Materials and Method}

Descriptive analytic study design was conducted among women attending outpatient clinics at maternity hospitals to assess their knowledge and practices about family planning. The study was performed from October 2019 to March 2020 at maternity hospitals in Baghdad city. Non probability (purposive sample) used to collect the data from (79) women. A questionnaire was designed by the researcher to assess women's knowledge and practices about family planning. A pilot study conducted in order to determine the reliability of the questionnaire in a sample of (20) women who excluded from the study sample $(\mathrm{r} 1=0.85)$. Content validity was determined through a panel of (8) experts their experience mean and SD was $26.6 \pm 5.5$. The data was collected after obtaining the agreement from women to participant in this study. The study instrument was consisted of three parts which include: Socio demographic characteristics, women's knowledge about family planning and women's practices about family planning. Data are analyzed through the use of SPSS (Statistical Process for Social Sciences) version 20 .

\section{Results}

Table (1): Distribution of Study Sample According to Socio-demographic Characteristics

\begin{tabular}{|c|c|c|}
\hline Socio Demographic Characteristics & $\mathbf{F}$ & $\%$ \\
\hline \multicolumn{3}{|l|}{ Age/years } \\
\hline$<20$ & 1 & 1.3 \\
\hline $20-29$ & 21 & 26.6 \\
\hline $30-39$ & 39 & 49.4 \\
\hline $40-49$ & 18 & 22.8 \\
\hline Total & 79 & 100 \\
\hline \multicolumn{3}{|c|}{ Mean=33.94 SD=6.2 } \\
\hline \multicolumn{3}{|l|}{ Duration of marriage/years } \\
\hline $1-5$ & 23 & 29.1 \\
\hline 6-10 & 34 & 43.0 \\
\hline $11-15$ & 11 & 13.9 \\
\hline $16-20$ & 7 & 8.9 \\
\hline$>21$ & 4 & 5.1 \\
\hline Total & 79 & 100 \\
\hline \multicolumn{3}{|l|}{ Mean=8.7 SD=5.7 } \\
\hline \multicolumn{3}{|l|}{ Age of last child/years } \\
\hline $1-4$ & 63 & 79.7 \\
\hline 5-8 & 11 & 13.9 \\
\hline $9-12$ & 5 & 6.3 \\
\hline Total & 79 & 100 \\
\hline \multicolumn{3}{|c|}{ Mean=4.3 SD=7.1 } \\
\hline \multicolumn{3}{|l|}{ Educational level } \\
\hline Secondary School & 6 & 7.6 \\
\hline Institute graduate & 17 & 21.5 \\
\hline College graduate & 55 & 69.6 \\
\hline Master and higher & 1 & 1.3 \\
\hline Total & 79 & 100 \\
\hline
\end{tabular}

This table illustrates that the highest percentage (49.4\%) of women's age were (30-39) years. Regarding duration of marriage the higher percentage $(43 \%)$ of them were (6-10) years. Regarding educational level more than half of them $(69.6 \%)$ were graduated from college. 
Table (2) Women's Knowledge about Family Planning Method

\begin{tabular}{|c|c|c|c|c|c|c|c|c|}
\hline \multirow{2}{*}{ No. } & \multirow{2}{*}{ Item } & \multicolumn{2}{|c|}{ Know } & \multicolumn{2}{|c|}{ Don't know } & \multirow{2}{*}{ MS } & \multirow{2}{*}{ RS } & \multirow{2}{*}{ Ass } \\
\hline & & $\mathbf{F}$ & $\%$ & $\mathbf{F}$ & $\%$ & & & \\
\hline A & \multicolumn{8}{|l|}{ Family planning method } \\
\hline 1 & Complex Contraceptive Pills & 62 & 78.5 & 17 & 21.5 & 1.78 & 89 & $\mathrm{H}$ \\
\hline 2 & Mini Pills & 33 & 41.8 & 46 & 58.2 & 1.41 & 70.5 & $\mathrm{~L}$ \\
\hline 3 & Types of Contraceptive Injection & 34 & 43 & 45 & 57 & 1.43 & 71.5 & $\mathrm{~L}$ \\
\hline 4 & Intrauterine devices & 44 & 55.7 & 35 & 44.3 & 1.55 & 77.5 & M \\
\hline 5 & Male Condom & 52 & 65.8 & 27 & 34.2 & 1.65 & 82.5 & M \\
\hline 6 & Female condom & 45 & 57 & 34 & 43 & 1.56 & 78 & $\mathrm{~L}$ \\
\hline 7 & Tubal Ligation & 54 & 68.4 & 25 & 31.6 & 1.68 & 84 & M \\
\hline 8 & Vasectomy & 52 & 65.8 & 27 & 34.2 & 1.65 & 82.5 & M \\
\hline B & Ideal pregnancies spacing & 36 & 45.6 & 43 & 54.4 & 1.45 & 72.5 & $\mathrm{~L}$ \\
\hline & Total & 50 & 63.3 & 29 & 36.7 & 1.63 & 81.5 & $\mathbf{M}$ \\
\hline
\end{tabular}

(M.S) mean score (R.S) relative sufficiency (Ass.) assessment $($ Low= $\geq 75)$, (Moderate= 75.1-87.5), $($ High= 87.6-100)

This table shows that there are a low level of relative sufficiency and mean score regarding items No.(2,3), while there are a high level of relative sufficiency and mean score regarding items No. (1). Also there are a low level of relative sufficiency and mean score regarding items No. (B). Also the total knowledge relative sufficiency and mean score is moderate level.

\section{Table (3) Women's Sources of Knowledge about Family Planning Method}

\begin{tabular}{|c|l|c|c|}
\hline No. & Item & F & \% \\
\hline 1 & Doctor & 16 & 20.3 \\
\hline 2 & Nurse & 2 & 2.5 \\
\hline 3 & Internet media & 27 & 34.2 \\
\hline 4 & Experience & 4 & 5 \\
\hline 5 & Reading & 12 & 15.2 \\
\hline 6 & Friend and Family & 18 & 22.8 \\
\hline & Total & $\mathbf{7 9}$ & $\mathbf{1 0 0}$ \\
\hline
\end{tabular}

This table illustrates that the highest percentage (34.2\%) of women's sources of knowledge were from the internet and media.

\section{Table (4) Women's Practices toward Family Planning Method}

\begin{tabular}{|l|l|c|c|}
\hline No. & Item & F & $\%$ \\
\hline A & Type of family planning & \multicolumn{2}{|l|}{} \\
\hline 1 & Natural Family planning method & 4 & 5.1 \\
\hline 2 & Contraceptive Pills & 7 & 8.9 \\
\hline 4 & Injection & 1 & 1.3 \\
\hline 5 & Intrauterine devices & 19 & 24.1 \\
\hline 6 & Male Condom & 13 & 16.5 \\
\hline 7 & Female condom & 1 & 1.3 \\
\hline 8 & Tubal Ligation & 1 & 1.3 \\
\hline & Didn't use & 33 & 41.8 \\
\hline B & Women choose type based on & & \\
\hline 1 & Doctor & 71 & 10.1 \\
\hline 2 & Couple & 1 & 8.9 \\
\hline 3 & Experience & 27 & 34.2 \\
\hline 5 & Family and Friends & 79 & 100 \\
\hline 6 & Didn't use & 71.8 \\
\hline & Total & & \\
\hline & & 73 & \\
\hline
\end{tabular}

This table shows the highest percentage $(24.2 \%)$ of women who used a family planning chooses Intrauterine devices, and their choice was based on Family and Friends. 


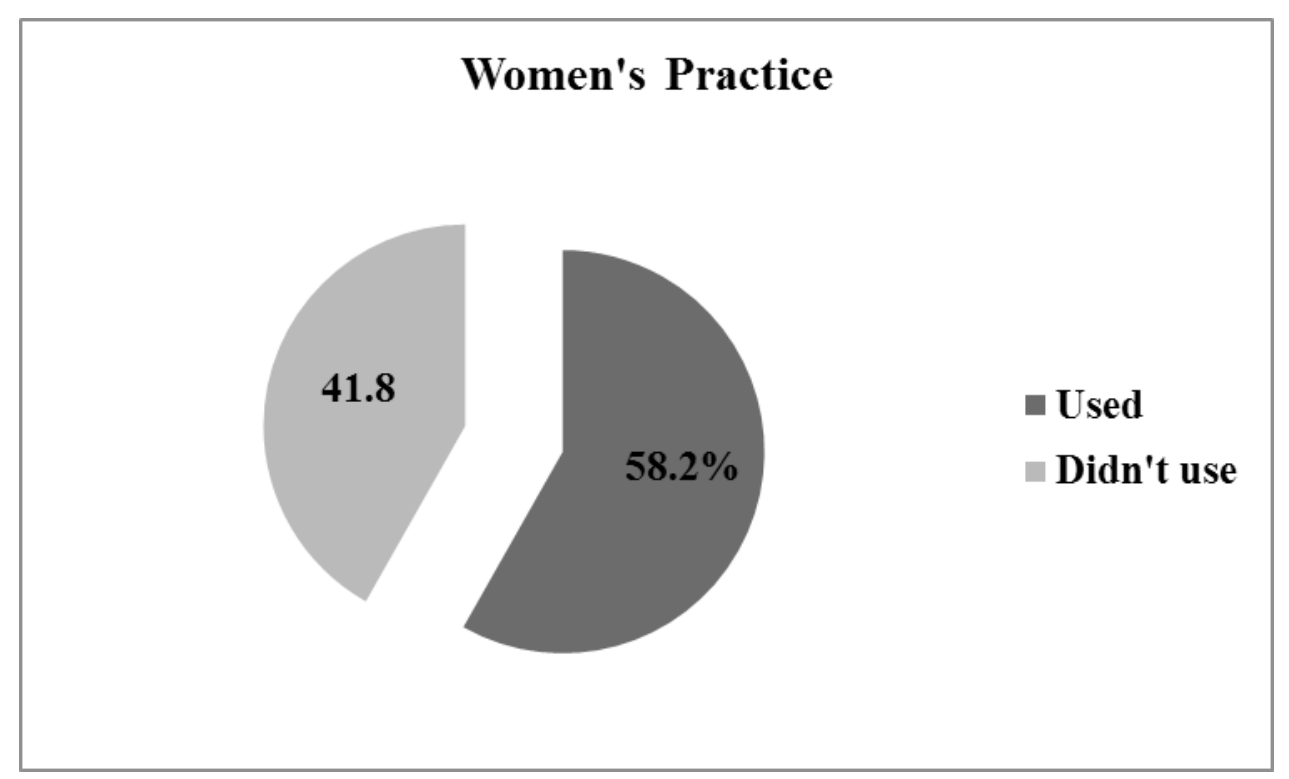

Figure (1) Women's Practice toward Family Planning Method

Table (5): Association between Women's Knowledge and Practices with Socio-Demographic Variables

\begin{tabular}{|c|c|c|c|c|c|c|c|c|c|}
\hline \multirow{2}{*}{ Women's Practice } & \multirow{2}{*}{ Women's Knowledge } & \multicolumn{2}{|c|}{ Know } & \multicolumn{2}{|c|}{ Don't know } & \multicolumn{3}{|c|}{ Chi square statistics } & \multirow{2}{*}{ Sig. } \\
\hline & & $\mathbf{F}$ & $\%$ & $\mathbf{F}$ & $\%$ & Value & df & P-value & \\
\hline \multicolumn{2}{|l|}{ Used } & 30 & 60 & 16 & 55.2 & \multirow{2}{*}{.176} & \multirow{2}{*}{1} & \multirow{2}{*}{.67} & \multirow{2}{*}{ Ns } \\
\hline \multicolumn{2}{|l|}{ Didn't use } & 20 & 40 & 13 & 44.8 & & & & \\
\hline \multirow{2}{*}{\multicolumn{2}{|c|}{$\begin{array}{l}\text { Women's Knowledge } \\
\text { Socio-demographic variables }\end{array}$}} & \multicolumn{2}{|c|}{ Know } & \multicolumn{2}{|c|}{ Don't know } & \multicolumn{3}{|c|}{ Chi square statistics } & \multirow{2}{*}{ Sig. } \\
\hline & & $\mathbf{F}$ & $\%$ & $\mathbf{F}$ & $\%$ & Value & df & P-value & \\
\hline \multirow{4}{*}{ Age/years } & $<20$ & 1 & 2 & 0 & 0 & \multirow{4}{*}{2.8} & \multirow{4}{*}{3} & \multirow{4}{*}{.41} & \multirow{4}{*}{ Ns } \\
\hline & $20-29$ & 12 & 24 & 9 & 31 & & & & \\
\hline & $30-39$ & 23 & 46 & 16 & 55.2 & & & & \\
\hline & $40-49$ & 14 & 28 & 4 & 13.8 & & & & \\
\hline \multirow{4}{*}{ Educational level } & Secondary School & 2 & 4 & 4 & 13.8 & \multirow{4}{*}{4.4} & \multirow{4}{*}{3} & \multirow{4}{*}{.21} & \multirow{4}{*}{ Ns } \\
\hline & Institute graduate & 11 & 22 & 6 & 20.7 & & & & \\
\hline & College graduate & 37 & 74 & 18 & 62.1 & & & & \\
\hline & Master and higher & 0 & 0 & 1 & 3.4 & & & & \\
\hline \multirow{2}{*}{\multicolumn{2}{|c|}{$\begin{array}{l}\text { Women's Knowledge } \\
\text { Socio-demographic variables }\end{array}$}} & \multicolumn{2}{|c|}{ Used } & \multicolumn{2}{|c|}{ Didn't use } & \multicolumn{3}{|c|}{ Chi square statistics } & \multirow{2}{*}{ Sig. } \\
\hline & & $\mathbf{F}$ & $\%$ & $\mathbf{F}$ & $\%$ & Value & df & P-value & \\
\hline & $<20$ & 0 & 0 & 1 & 3 & & & & \\
\hline A or/nomer & $20-29$ & 9 & 19.6 & 12 & 36.4 & 46 & 2 & 2 & $N$ \\
\hline Age/years & $30-39$ & 26 & 56.5 & 13 & 39.4 & 4.0 & 3 & .2 & NS \\
\hline & $40-49$ & 11 & 23.9 & 7 & 21.2 & & & & \\
\hline & Secondary School & 5 & 10.9 & 1 & 3 & & & & \\
\hline [duotion 11 on & Institute graduate & 9 & 19.6 & 8 & 24.2 & 21 & 2 & 27 & No \\
\hline Eaucational level & College graduate & 32 & 69.6 & 23 & 69.7 & 3.1 & 3 & .31 & NS \\
\hline & Master and higher & 0 & 0 & 1 & 3 & & & & \\
\hline
\end{tabular}

(df) degree of freedom, (Sig) significant Probability value $(\mathrm{P}<0.05)$, (NS) Non Significant, (s) significant. 
This table shows that there are no statistical significant between women's knowledge and practice with socio-demographic variables toward family planning method

\section{Discussion}

The findings of current study show about half of women's age were (30-39) years, more than one third married for (6-10) years, their last child's age was (1-4 years). Regarding educational level more than two third was graduated from college.

Agha and Rasheed stated that Iraq, like some other developing countries, people have still appreciates early marriage, large families and a role for woman in the home. In addition, the previous Iraqi government, especially in the 1980s, encouraged high fertility to compensate for casualties during its wars. Until the middle of the past decade, the Iraqi Ministry of Health neglected family planning in the country. This explains why the crude birth rate in Iraq was one of the highest in the world in the late 1980s and early 1990s. At the time of their study, health services in Iraq, including family planning, were almost free in government clinics, when these were available, but not all family planning method were available in family planning clinics. Therefore, for many mothers, the sources of family planning services were private clinics and pharmacies due to the limited services $^{[7]}$.

The current study found more than half of study sample have knowledge about family planning method, while they didn't know the ideal pregnancies spacing. This might be due to most of the study sample were graduate from college so they think in family planning are useful to be economically, self-sufficient and more likely to acquire greater confidence and personal control in marital relationships including the discussion of family size and contraceptive use. More than third of their source of knowledge were from the internet, and second higher percent from family and friends. This finding supported with a study who found more than third $(42.3 \%)$ of study participants had good knowledge, and (50.4\%) had good practice towards family planning ${ }^{[3]}$. another study reported that the higher percentage $(45 \%)$ of the women's source of information was from media, followed by $(15 \%)$ from internet/friends and relatives and ten percent from health professionals. This study finding also is consistent with a study who found (70\%) had gained knowledge of contraception from friends and relatives and (39\%) from TV and radio ${ }^{[9-10]}$.

Women's decision making to use contraceptive method is affected by many factors including knowledge gained from various sources. Blackstock and collegues found that the role of the social network regarding family planning generally to provide women contraceptive information and particularly to guide women to a specific contraceptive method. They found that the knowledge gained from health care providers especially social network members often enhanced or clarified their knowledge gained from other informal sources, ${ }^{[4]}$.

This study found more than half of study participant were use a family planning method, they choose intrauterine device and male condom as a higher percent. They choose the method based on advice from their family and friends.

The condom use was high rate compared to neighboring countries; this may be due to the free availability of condoms in Dohuk. However, similar rates of condom use have been reported in Iraq and the Islamic Republic of Iran and among Palestinian refugees ${ }^{[7]}$.

Many women want to delay pregnancy and avoid STIs, as options are difficult. There are many method available today, and more will be offered in the near future. The ideal method of contraception for many women should have the following characteristics: ease of use, safety, efficacy, minimal side effects, "nature", nonhormonal method, and immediate reversal. Currently, no single method of contraception offers everything ${ }^{[8]}$.

\section{Conclusion}

This study revealed that more than half of study sample have knowledge about family planning method and they used a family planning method. The most common type of family planning was intra uterine device. There are no statistical significant differences between level of knowledge and women's age or educational level. There are no statistical significant differences between women's knowledge and practice; also there are no statistical significant differences between women's knowledge and practice with sociodemographical variables.

Recommendation: This study findings shows the most women's source of knowledge from the internet and most of them choose a type of family planning based on 
family and friends advice so the researcher recommend to activate the role of health care professional especially doctors and nurses to provide scientific knowledge and counseling to couples to choose the most appropriate method.

Funding: This research was funded by Author. Moreover, I would like to thank all the women who participated in this study and pay tribute to them for their supporting this project.

Conflict of Interest: None declared

Ethical Approval: Not required

\section{References}

1. Pillitteri, A,: Maternal and Child health Nursing: Care of the Childbearing and Childrearing Family, $6^{\text {th }}$ ed., Lippincott Williams \& Wilkins Publishers, Philadelphia, 2010, 118-139.

2. Hamed, Z. F.; El-gazzar, A. F.; Moftah, F. M.: Knowledge, Attitude and Practice of Family Planning Method among Husbands in a Village of Assiut Governorate, The Egyptian Journal of Hospital Medicine, 2018, 73(4), 6489-6493.

3. Semachew Kasa, A.; Tarekegn, M.; Embiale, N.: Knowledge, attitude and practice towards family planning among reproductive age women in a resource limited settings of Northwest Ethiopia, BMC Research Notes, 2018, 11(577), 1-6. https:// doi.org/10.1186/s13104-018-3689-7

4. Blackstock, O. J.; Mba-Jonas, A.; Sacajiu, G. M.: Family planning knowledge: The role of social networks and primary care providers as information sources for African American women,
American Journal of Sexuality Education, 2010, 5(2), 128-143. https://doi.org/10.1080/10627197.2 010.491060 .

5. Kopp, D. M.; Bula, A., Maman, S.; Chinula, L.; Tsidya, M.; Mwale, M.; Tang, J. H.: Influences on birth spacing intentions and desired interventions among women who have experienced a poor obstetric outcome in Lilongwe Malawi: A qualitative study. BMC Pregnancy and Childbirth, 2018, 18(1), 1-11. https://doi.org/10.1186/s12884018-1835-9

6. United Nations reproductive health agency (UNFPA), 2014, Available from https://iraq.unfpa. org/en/news/strengthening-and-scaling-familyplanning-services-iraq

7. Agha,S.; Rasheed,B.: Family planning and unmet need among Iraqi Kurds, Eastern Mediterranen Health Journal, 2007, 13(6),1328-1390.

8. Ricci,S.,Kyle,T.: Maternity and pediatric nursing, 2nd edition, Lippincott Williams \& Wilkins, Philadelphia, 2013, 108.

9. Qazi, M.; Saqib, N.; Gupta, S.: Knowledge, attitude and practice of family planning among women of reproductive age group attending outpatient department in a tertiary centre of Northern India. International Journal of Reproduction, Contraception, Obstetrics and Gynecology, 2019, 8(5), 1775. https://doi.org/10.18203/2320-1770. ijrcog20191531

10. Srivastava R; Srivastava DK; Jina R; Srivastava K; Sharma N, Sana S.: Contraceptive knowledge, attitude and practice (KAP Survey). J Obstet Gynecol India, 2005, 55(6),546-550. 